\title{
Prospective study of physical activity and risk of squamous cell carcinoma of the skin
}

Petra H Lahmann ${ }^{1 *}$, Anne Russell ${ }^{1}$ and Adèle C Green ${ }^{1,2}$

\begin{abstract}
Background: The relationship between physical activity and risk of cutaneous squamous cell carcinoma (SCC) is unknown and difficult to investigate due to confounding by sun exposure. We prospectively examined the association of recreational and occupational physical activity and incidence of SCC accounting for photoaging and other risk factors.

Methods: We used available information on physical activity from the Australian population-based Nambour Skin Cancer Study comprising 1,171 adults aged 25-75 years at baseline (1992). In sex-stratified analyses (person-based and tumor-based) we estimated the associations between type of activity and incidence of SCC prospectively to 2007.

Results: During 16 years of follow-up, 98 men and 90 women newly developed SCC. We found no significant association between recreational activity measures and SCC after controlling for potential confounding factors including indicators of sun exposure. In men, the observed risk pattern was however suggestive of elevated risk with increasing total hours of recreational activity (compared to inactive men, RR $(95 \% \mathrm{Cl}) 0.89(0.54,1.46)$ for $\leq 1.5$ hrs/wk; $1.29(0.82,2.04)$ for $\leq 4.0 \mathrm{hrs} / \mathrm{wk} ; 1.33(0.86,2.05)>4.0 \mathrm{hrs} / \mathrm{wk})$, while among women, higher level of occupational activity (standing and manual versus sedentary work activities) was associated with a reduced incidence of SCC tumors ( $P$ trend $=0.03$ ).
\end{abstract}

Conclusions: Despite some suggestion that recreational activity in men and occupational activity in women are related to occurrence of SCC, there is no firm support for a role of physical activity in the development of cutaneous SCC.

\section{Background}

Squamous cell carcinoma (SCC) is the second most common skin cancer after basal cell carcinoma (BCC). High cumulative ultraviolet (UV) radiation exposure is the major environmental risk factor for SCC along with other host factors that are markers of UV susceptibility such as fair skin and fair/red hair [1-3].

Physical activity influences the risk of several types of cancer. Existing evidence strongly supports the role of regular physical activity in reducing risk of cancers of the colon, breast, and endometrium, and to a lesser extent cancers of the lung and pancreas [4]. It is also suggested that a similar association may exist for other cancers [5].

Proposed biological mechanisms through which physical activity may affect cancer risk or progression include

\footnotetext{
* Correspondence: Petra.Lahmann@qimr.edu.au

'Queensland Institute of Medical Research, Cancer and Population Studies,

300 Herston Road, Herston, Brisbane 4006, Australia Full list of author information is available at the end of the article
}

changes in sex hormones, metabolic hormones and growth factors, inflammatory markers, and immune function $[5,6]$. Beneficial effects of physical activity are also conceivable for skin cancer, specifically those that improve immune function and those that increase detoxification of reactive oxygen species or increase DNA repair, thus reducing sun exposure-induced DNA damage $[5,7,8]$.

Data on the association between physical activity and skin cancer are so scarce however [9], that conclusions on physical activity and body fatness as possible determinants of skin cancer could not be reached for lack of evidence [4]. A potential positive association between amount of recreational physical activity and skin cancer has been suggested in athletes, known to have very high UV radiation exposure levels while performing outdoor sports [10-12]. In addition to sun exposure, exerciseinduced immunosuppression has also been suggested to
Ciomed Central 
increase risk of keratinocyte carcinomas and cutaneous melanoma in athletes $[12,13]$.

The very few population-based studies on recreational or occupational physical activity and skin cancer incidence are confined to melanoma [9] or combined keratinocyte cancers (SCC and BCC) [14-16]. As for athletes, in the general population confounding of the association by sun exposure remains a potential explanation for any positive associations [16]. Evidence on occupational sun exposure as a factor associated with keratinocyte cancers remains unclear based on the few investigations exploring outdoor work or occupations in relation to these cancers [17-19].

Our aim was to examine the associations of recreational and occupational physical activity and incidence of SCC in a long-term community-based cohort study of skin cancer in Australia taking into account potential confounding by sun exposure and other established risk factors for SCC.

\section{Methods}

Study population and data collection

In this prospective study, 1,621 residents of the Queensland township of Nambour, who were originally randomly selected from the population-based electoral roll [20] and who participated in the Nambour Skin Cancer Prevention Trial (1992-1996) [21,22] were followed up until 2007. Ethical approval was obtained from the ethics committee of the Queensland Institute of Medical Research.

\section{Assessment and classification of physical activity measures}

At baseline in 1992, participants underwent a physical examination (height and weight were measured by trained study personnel) and completed a health and fitness questionnaire including information on recreational physical activity, outdoor behavior, phenotype, previous skin cancer history (before 1992) and other personal characteristics including occupation.

\section{Recreational physical activity}

The physical activity questionnaire items were adapted from the National Health Survey 1989-90 [23,24]. Participants were asked the frequency and duration (in hours and minutes) of three categories of exercise done for sport, recreation or fitness during the past 2 weeks: 1 ) walking, 2) any exercise causing a moderate increase in heart rate or breathing, and 3) any exercise causing a large increase in heart rate or breathing. The latter two are referred to as moderate activity and vigorous activity in this study. Information was not recorded about the type of activities undertaken, but reported against each of the three categories above. Values for the individual categories were summed to derive total recreational activity reported here as hours per week (hrs/wk).

Metabolic equivalent (MET) values, defined as the ratio of work metabolic rate to a standard resting metabolic rate of $1.0(4.184 \mathrm{~kJ}) / \mathrm{kg} /$ hour were assigned for walking (light activity), moderate activity, and vigorous activity (3, 5, and 9 respectively) according to the Compendium of Physical Activities [25], and multiplied by the hours exercised at that intensity level per week, to obtain MET-hrs/wk of activity for each level and combined (total recreational activity).

All measures of recreational activity were used as categorical variables due to large proportions of zero values. The reference category for each variable included individuals who reported no activity, i.e. zero hours or minutes. Active study participants were ranked into approximately equal thirds based on sex-specific cut-points, except for the variable vigorous activity which had only two categories (non-active/active) due to small numbers of study participants practising vigorous sporting activities.

\section{Occupational physical activity}

Occupational physical activity was based on reported main lifetime occupations, coded according to the Australian Standard Classification of Occupations [26] and independently assigned by two of the authors (PHL, AR) as follows: sedentary, standing or manual (including heavy manual work).

\section{Endpoints and ascertainment of cases}

Incident squamous cell carcinoma (SCC) was identified through detailed assessment procedures described previously $[21,22,27]$. All SCCs were verified histologically. Two outcomes were used in the analyses: (a) incidence of persons affected by new SCCs diagnosed after the baseline 1992 skin examination survey through to 31 December 2007, in the person-years of follow-up accumulated between these dates; (b) incidence of SCC tumors in the same person-years follow-up time as above. SCC tumors and person-years of follow-up were counted until date of withdrawal from the study, date of death or 31 December 2007, whichever came first. This analysis included 188 persons with new SCC, 98 men and 90 women.

\section{Statistical Analysis}

For person-based analysis, relative risks (RRs) with 95\% confidence intervals (95\% CI) of SCC incidence for each categorical physical activity measure were estimated by generalised linear models, specifying Poisson distribution with a robust error variance [28] and person-years of follow-up as offset. For tumor-based analyses, RRs (95\% CI) were derived using generalised linear models with negative binomial distribution. The negative binomial distribution has been recommended for analysing nonnegative integer data which is overdispersed, usually due to aggregation of events within individuals [29]. All analyses were stratified by sex and multivariable models were simultaneously adjusted for the following established risk factors and potential confounders: age, history 
of skin cancer (before 1992), elastosis of the neck (clinical measure of photoaging), and freckling of the back. Treatment (betacarotene supplements and/or daily sunscreen) allocation in the trial 1992-1996 was included as a study design variable. We did not adjust for natural skin or hair colour, or tanning ability in the multivariable model because these innate characteristics were captured when degree of photoaging, a composite measure of sun sensitivity and cumulative sun exposure, was included in the model [30].

To test for linear trend across levels of physical activity, we modelled the sex-specific median value in each category as a continuous variable. To examine the potential effect modification of the physical activity-SCC association by sex or history of skin cancer, interaction terms for total recreational activity with sex or skin cancer history were tested. A $P$ value for interaction was calculated, referring to the interaction term of the sex variable or the skin cancer history variable and total recreational activity (categorical) over the entire cohort. Neither of the interaction terms was statistically significant $(P>0.05)$. A sex-stratified analysis was performed due to expected differences in physical activity patterns between men and women.

\section{Results}

For the present study, participants with missing data on physical activity items $(\mathrm{n}=282)$ and body mass index $\left(\mathrm{BMI}, \mathrm{kg} / \mathrm{m}^{2}\right)(\mathrm{n}=168)$ were excluded, leaving an analytical cohort of 1,171 men and women. Participants who were excluded from the analysis tended to be younger than their included counterparts, but the difference in mean age at baseline was only statistically significant in men ( 47.2 vs 50.5 yrs). Further, excluded women were more likely to have a lower education, while excluded men were more likely to have a lower grading of clinical elastosis and were less likely to have a keratinocyte cancer prior to 1992 compared to their respective counterparts included in the study.

Study participants aged 25 to 75 years at baseline (1992) were followed for an average period of $14.4( \pm 3.8)$ years, yielding a total of 16887 person-years. Characteristics of the study population stratified by case status and sex are presented in Table 1, 2. Compared to those unaffected, persons with SCC were on average older, more likely to burn than tan on strong sun exposure, have a higher grade of freckling on the back, and severe clinical elastosis of the neck (Table 1). Study participants with or without SCC did not differ in their leisure or occupational sun exposure in 1992 or their cumulative sun exposure over time (data not shown). Twenty-eight percent had a history of keratinocyte cancer (SCC and/or BCC) before the baseline examination in 1992 .

At baseline, $33 \%$ of all women and $40 \%$ of all men were classified as physically inactive, i.e. they did not report any time spent walking or performing more moderate/vigorous recreational activities. Among physically active study participants, men reported more hours of total recreational activity than women. On average, active men $(\mathrm{n}=304)$ spent a mean (SD) of $4.2(4.5) \mathrm{hrs} /$ wk and active women $(\mathrm{n}=443) 2.9(3.3) \mathrm{hrs} / \mathrm{wk}$ on any recreational activity. Walking was the predominant activity (men: 2.3 (3.7); women 1.9 (2.8) hrs/wk).

Women did not differ by case status in any of the recreational physical activity measures, whereas males with SCC reported more hours of walking, but less hours of vigorous exercise, compared to their counterparts with no SCC (Table 2). Regarding occupational activity, affected females tended to have a higher proportion of manual activity and lower proportion of sedentary occupations than nonaffected, but this difference did not reach statistical significance. Overall, women in manual activity tended to do their work mainly indoors $(45 \%)$ or both indoors and outdoors (47\%), whereas men in manual activity performed their work predominantly outdoors (66\%).

In age-adjusted and multivariable-adjusted models, neither total recreational physical activity nor any individual type of activity or MET-hrs were significantly associated with risk of SCC when analysed by persons (Table 3) or tumor counts (Tables 4) in both sexes.

Among men, the risk estimates for total recreational activity and walking suggested a slightly increased risk in SCC, but they were not statistically significant (except for walking 1.2-3.5 hrs/wk, person-based) and there were no dose-response trends. Occupational activity was not significantly related to SCC in men, but was in women. With increasing work activity, women had a reduced incidence of SCC $(P$ trend $=0.03)$ in the tumor-based analysis. This association did not reach statistical significance in the person-based analysis.

In additional analyses (data not shown), neither stratification of tumors according to whether they occurred on chronically or occasionally sun-exposed skin sites, nor mutual adjustment of recreational and occupational activity materially affected the risk estimates in the respective physical activity models, with one exception. In men, the recreational activity-SCC association based on tumor counts was slightly stronger after adjustment for occupational activity (RR $(95 \% \mathrm{CI})$ low, medium, high vs none: 1.36 (0.74, 2.49), 1.55 (0.81-2.96), 2.01 (1.09$\left.3.69) ; \mathrm{p}_{\text {trend }}=0.032\right)$. Finally, for completeness, we assessed the use of sunscreen (non-user/irregular user/ regular user) and found no significant difference in sunscreen use across levels of recreational or occupational activity in either men or women, though compared with inactive women, women with active recreations tended to be more regular sunscreen users (data not shown). 
Table 1 Characteristics by skin cancer status, the Nambour Skin Cancer Study $(\mathbf{N}=1,171)$

\begin{tabular}{|c|c|c|c|c|c|c|}
\hline \multirow[t]{2}{*}{ Characteristics } & \multicolumn{3}{|c|}{ Women } & \multicolumn{3}{|c|}{ Men } \\
\hline & $\operatorname{SCC}(n=90)$ & No SCC $(n=575)$ & $p$-value & $\operatorname{SCC}(n=98)$ & No SCC $(n=408)$ & $\mathrm{p}$-value \\
\hline & \multicolumn{6}{|c|}{ Mean (SD) } \\
\hline Age (years) & $57.3(9.9)$ & $48.1(12.1)$ & $<0.001$ & $59.7(11.7)$ & $48.3(13.0)$ & $<0.001$ \\
\hline \multirow[t]{2}{*}{$\mathrm{BMI}, \mathrm{kg} / \mathrm{m}^{2}$} & $26.2(5.0)$ & $25.8(4.7)$ & 0.515 & $26.6(3.8)$ & $26.5(3.6)$ & 0.868 \\
\hline & \multicolumn{6}{|c|}{$N(\%)$} \\
\hline History of skin cancer & $48(53.3)$ & $123(21.4)$ & $<0.001$ & $64(65.3)$ & $88(21.6)$ & $<0.001$ \\
\hline \multicolumn{7}{|l|}{ Education } \\
\hline High school only & $63(70.0)$ & $366(63.7)$ & 0.446 & $37(37.8)$ & $167(40.9)$ & 0.284 \\
\hline Certificate/diploma & $3(3.3)$ & $34(5.9)$ & & 31 (31.6) & $147(36.0)$ & \\
\hline University & $22(24.4)$ & $147(25.6)$ & & $22(22.4)$ & $59(14.5)$ & \\
\hline Trade/other & $2(2.2)$ & $28(4.9)$ & & $8(8.2)$ & $35(8.6)$ & \\
\hline \multicolumn{7}{|l|}{ Pack-years of smoking } \\
\hline None & $56(62.2)$ & $383(66.6)$ & 0.599 & $35(35.7)$ & $181(44.4)$ & 0.115 \\
\hline $1-7$ & $13(14.4)$ & $92(16.0)$ & & $16(16.3)$ & $65(15.9)$ & \\
\hline$>7-20$ & $10(11.1)$ & $49(8.5)$ & & $13(13.3)$ & $67(16.4)$ & \\
\hline$>20$ & $11(12.2)$ & $51(8.9)$ & & $34(34.7)$ & $95(23.3)$ & \\
\hline \multicolumn{7}{|l|}{ Tanning ability of skin } \\
\hline Always burn & $33(36.7)$ & $130(22.6)$ & 0.003 & $29(29.6)$ & $55(13.5)$ & $<0.001$ \\
\hline Burn then tan & $54(60.0)$ & $377(65.6)$ & & $62(63.3)$ & $310(76.2)$ & \\
\hline Only tan & $3(3.3)$ & $68(11.8)$ & & $7(7.1)$ & $42(10.3)$ & \\
\hline \multicolumn{7}{|c|}{ Painful sunburns throughout life (1992) } \\
\hline Never & $10(11.1)$ & $62(10.8)$ & 0.084 & $15(15.3)$ & $48(11.8)$ & 0.798 \\
\hline Once & $21(23.3)$ & $114(19.8)$ & & $14(14.3)$ & $55(13.5)$ & \\
\hline 2-5 times & $29(32.2)$ & $263(45.7)$ & & $40(40.8)$ & $176(43.2)$ & \\
\hline More than 5 times & $30(33.3)$ & $136(23.7)$ & & 29 (29.6) & $128(31.4)$ & \\
\hline \multicolumn{7}{|c|}{ Freckling of the back (1992) ${ }^{a}$} \\
\hline $\mathrm{Nil}$ & $18(20.5)$ & $197(35.1)$ & 0.001 & 19 (19.6) & $125(32.0)$ & $<0.001$ \\
\hline Mild & $29(33.0)$ & $215(38.3)$ & & $25(25.8)$ & $137(35.0)$ & \\
\hline Moderate & $30(34.1)$ & $103(18.3)$ & & $20(20.6)$ & $76(19.4)$ & \\
\hline Severe & $11(12.5)$ & $47(8.4)$ & & $33(34.0)$ & $53(13.6)$ & \\
\hline \multicolumn{7}{|c|}{ Clinical elastosis of the neck (1992) ${ }^{a}$} \\
\hline $\mathrm{Nil}$ & $5(5.6)$ & $160(27.8)$ & $<0.001$ & $2(2.1)$ & $72(17.7)$ & $<0.001$ \\
\hline Mild & $38(42.2)$ & $282(49.0)$ & & 35 (36.1) & $205(50.4)$ & \\
\hline Severe & $47(52.2)$ & $133(23.1)$ & & $60(61.9)$ & 130 (31.9) & \\
\hline
\end{tabular}

${ }^{a}$ Column percentages may not sum to $100 \%$ due to missing values (freckling of the back: women $n=15$, men $n=18$; elastosis: men $n=2$ )

\section{Discussion}

In this large prospective study of Australian adults, recreational physical activity was not significantly associated with development of cutaneous SCC when adjusted for other risk factors including indicators of sun exposure. In men, we observed a suggestive pattern of elevated risk with increasing hours of total activity or walking, but trends did not reach statistical significance. In contrast to recreational activity, higher occupational activity, i.e. standing or manual activity, was significantly associated with reduced risk of SCC among women in tumor-based, but not in person-based analysis.

To our knowledge, this study is the first to investigate the association between physical activity, both recreational and occupational, and cutaneous SCC and therefore, comparisons with other relevant reports are limited. Our observation of a suggestive positive association for recreational activity in men corroborates the finding from a large Danish prospective study [16] showing a highly significant positive association of leisure activity with keratinocyte cancers in most active men, but not in women. Schnohr and colleagues [16] speculated that the sex difference found in their study may be due to more outdoor exercise, less clothing, and less use of sunscreen in men than women. In their study on risk of cancer in general, the leisure activity-skin cancer association was not adjusted for outdoor sun exposure or any proxy measure reflecting sun exposure, and thus may be confounded by UV radiation. In contrast, in our SCC-study, we accounted for clinical elastosis, a marker of photoaging due to 
Table 2 Type of physical activity by skin cancer status, the Nambour Skin Cancer Study $(\mathbf{N}=1,171)$

\begin{tabular}{|c|c|c|c|c|c|c|c|}
\hline \multirow{2}{*}{\multicolumn{2}{|c|}{ Type of physical activity }} & \multicolumn{3}{|c|}{ Women } & \multicolumn{3}{|c|}{ Men } \\
\hline & & SCC $(n=90)$ & No SCC $(n=675)$ & p-value & SCC $(n=98)$ & No SCC $(n=408)$ & $\mathrm{p}$-value \\
\hline \multicolumn{8}{|c|}{ Recreational activity, total (hrs/wk) } \\
\hline None & & $32(35.6)$ & $190(33.0)$ & 0.823 & $33(33.7)$ & 169(41.4) & 0.093 \\
\hline$F \leq 1$ & $M \leq 1.5$ & $18(20.0)$ & $135(23.5)$ & & $17(17.3)$ & $88(21.6)$ & \\
\hline$F \leq 3$ & $M \leq 4$ & $19(21.1)$ & $131(22.8)$ & & $21(21.4)$ & $81(19.9)$ & \\
\hline$F>3$ & $M>4$ & $21(23.3)$ & $119(20.7)$ & & $27(27.6)$ & $70(17.2)$ & \\
\hline \multicolumn{8}{|c|}{ Walking (hrs/wk) } \\
\hline None & & $40(44.4)$ & $278(48.3)$ & 0.479 & $43(43.9)$ & $261(64.0)$ & $<0.001$ \\
\hline $\mathrm{F}<1$ & $M<1.2$ & $17(18.9)$ & $88(15.3)$ & & $11(11.2)$ & $57(14.0)$ & \\
\hline$F<2.5$ & $M<2.5$ & $13(14.4)$ & $107(18.6)$ & & $20(20.4)$ & $46(11.3)$ & \\
\hline$F \geq 2.5$ & $M \geq 2.5$ & $20(22.2)$ & $102(17.7)$ & & $24(24.5)$ & $44(10.8)$ & \\
\hline \multicolumn{8}{|c|}{ Moderate activity (hrs/wk) } \\
\hline None & & $74(82.2)$ & $434(75.5)$ & 0.374 & $72(73.5)$ & $290(71.1)$ & 0.895 \\
\hline$F<1.5$ & $M<1.75$ & $8(8.9)$ & $72(12.5)$ & & $13(13.3)$ & $59(14.5)$ & \\
\hline$F \geq 1.5$ & $M \geq 1.75$ & $8(8.9)$ & $69(12.0)$ & & $13(13.3)$ & $59(14.5)$ & \\
\hline \multicolumn{8}{|c|}{ Vigorous activity (hrs/wk) } \\
\hline None & & $85(94.4)$ & $527(91.7)$ & 0.363 & $92(93.9)$ & $350(85.8)$ & 0.030 \\
\hline$F \leq 8$ & $M \leq 12$ & $5(5.6)$ & $48(8.3)$ & & $6(6.1)$ & $58(14.2)$ & \\
\hline \multicolumn{8}{|c|}{ Recreational activity, total (MET-hr/wk) } \\
\hline None & & $32(35.6)$ & $190(33.0)$ & 0.911 & $33(33.7)$ & $169(41.4)$ & 0.417 \\
\hline$F \leq 3.7$ & $M \leq 6$ & $19(21.1)$ & $132(23.0)$ & & 19 (19.4) & $81(19.9)$ & \\
\hline$F \leq 10.7$ & $M \leq 18$ & $21(23.3)$ & $125(21.7)$ & & $23(23.5)$ & $82(20.1)$ & \\
\hline$F>10.7$ & $M>18$ & $18(20.0)$ & $128(22.3)$ & & $23(23.5)$ & 76 (18.6) & \\
\hline \multicolumn{8}{|c|}{ Occupational activity } \\
\hline Sedentary & & 25 (29.8) & $192(37.4)$ & 0.073 & $23(24.2)$ & $104(29.1)$ & 0.200 \\
\hline Standing & & $9(10.7)$ & 84 (16.3) & & 37 (38.9) & $146(40.8)$ & \\
\hline Manual & & $50(59.5)$ & $238(46.3)$ & & 35 (36.8) & $108(30.2)$ & \\
\hline
\end{tabular}

cumulative sun exposure [30]. This may explain the lack of an independent effect of any of the recreational activity measures on SCC in our data.

Findings from two other reports examining incidence of melanoma or keratinocyte cancers in women with higher versus lower recreational activity during adult life are equivocal. In a study of female college alumnae from the US, there was no difference in the lifetime occurrence of keratinocyte cancers and melanomas between former college athletes and nonathletes [31]. A Finnish registerbased study of life-long physical activity and cancer risk among female teachers indicated that teachers of physical education had a non-significant 2-fold higher standardized incidence ratio of melanoma compared to language teachers during the follow-up period 1967-91 [15]. Both investigations lack adjustment for sun exposure or any other potential confounder.

In the present study, physical activity at work was inversely and significantly associated with the development of SCC in women when tumor counts where considered. The person-based analysis suggested a similar protective effect with higher work activity. The lack of an association among men may be related to the overall higher proportion of manual activity in women (48\% vs $32 \%)$ which was predominantly performed indoors and included home duties, in contrast to men. Thus, some potentially beneficial effects of a higher activity level combined with lower outdoor sun exposure may have contributed to the reduced risk in women. Results from a large hospital-based case-control study of selected cancer sites indicated no effect of work activity assessed as energy expenditure and sitting time during work hours on risk of keratinocyte cancers [14]. Compatible with our investigation, the assessment of occupational activity level was based on job titles, but the cancer outcome was SCC and BCC combined, and sun exposure was not accounted for. Except for this single study [14], we found no other relevant evidence in the literature on occupational activity and risk of SCC.

Similar to risk of internal cancers, any reduction in risk of SCC in persons with higher physical activity levels may be due to compensatory mechanisms by the physical activity, i.e. beneficial effects, specifically when sun-exposure is accounted for as in our study. However, this cannot fully explain the opposite tendency, i.e. towards a positive association between recreational 
Table 3 Relative risks (RRs) and 95\% Cl of SCC (1992-2007) according to type of physical activity, stratified by sex

\begin{tabular}{|c|c|c|c|c|c|c|c|}
\hline \multirow{2}{*}{\multicolumn{2}{|c|}{$\begin{array}{l}\text { Type of physical } \\
\text { activity } \\
\text { Recreational } \\
\text { activity, total (hrs/ } \\
\text { wk) }\end{array}$}} & $\begin{array}{l}\text { Women with } \\
\text { SCC/Total }\end{array}$ & $\begin{array}{c}\text { Age-adjusted RR } \\
(95 \% \mathrm{Cl})\end{array}$ & $\begin{array}{c}\text { Multivariable }{ }^{\mathrm{a}} \mathrm{RR} \\
(95 \% \mathrm{Cl})\end{array}$ & $\begin{array}{c}\text { Men with SCC/ } \\
\text { Total }\end{array}$ & $\begin{array}{c}\text { Age-adjusted RR } \\
(95 \% \mathrm{Cl})\end{array}$ & $\begin{array}{c}\text { Multivariable }^{\mathrm{a}} \mathrm{RR} \\
(95 \% \mathrm{Cl})\end{array}$ \\
\hline & & & $(n=665)$ & $(n=650)$ & & $(n=506)$ & $(n=486)$ \\
\hline \multicolumn{2}{|l|}{ None } & $32 / 222$ & Reference & Reference & $33 / 202$ & Reference & Reference \\
\hline$F \leq 1$ & $\begin{array}{l}M \leq \\
1.5\end{array}$ & $18 / 153$ & $0.88(0.53,1.48)$ & $0.92(0.56,1.53)$ & $17 / 105$ & $0.82(0.50,1.36)$ & $0.89(0.54,1.46)$ \\
\hline$F \leq 3$ & $\begin{array}{l}M \leq \\
4\end{array}$ & $19 / 150$ & $0.96(0.57,1.60)$ & $1.04(0.62,1.74)$ & $21 / 102$ & $1.23(0.78,1.94)$ & $1.29(0.82,2.04)$ \\
\hline$F>3$ & $\begin{array}{l}M> \\
4\end{array}$ & $21 / 140$ & $0.87(0.53,1.41)$ & $0.85(0.52,1.38)$ & $27 / 97$ & $1.45(0.93,2.25)$ & $1.33(0.86,2.05)$ \\
\hline \multicolumn{3}{|l|}{$\mathrm{p}$-trend } & 0.647 & 0.557 & & 0.053 & 0.135 \\
\hline \multicolumn{8}{|c|}{ Walking (hrs/wk) } \\
\hline \multicolumn{2}{|l|}{ None } & $40 / 318$ & Reference & Reference & $43 / 304$ & Reference & Reference \\
\hline$F<1$ & $\begin{array}{l}\mathrm{M}< \\
1.2\end{array}$ & $17 / 105$ & $1.30(0.81,2.10)$ & $1.36(0.85,2.17)$ & $11 / 68$ & $0.99(0.56,1.74)$ & $1.04(0.59,1.82)$ \\
\hline $\begin{array}{l}F< \\
2.5\end{array}$ & $\begin{array}{l}\mathrm{M}< \\
3.5\end{array}$ & $13 / 120$ & $0.81(0.44,1.46)$ & $0.99(0.55,1.78)$ & $20 / 66$ & $1.61(1.06,2.47)$ & $1.64(1.07,2.51)$ \\
\hline $\begin{array}{l}F \geq \\
2.5\end{array}$ & $\begin{array}{l}M \geq \\
3.5\end{array}$ & $20 / 122$ & $0.98(0.60,1.62)$ & $1.06(0.65,1.74)$ & $24 / 68$ & $1.63(1.06,2.50)$ & $1.37(0.90,2.08)$ \\
\hline \multicolumn{3}{|l|}{ p-trend } & 0.734 & 0.997 & & 0.026 & 0.142 \\
\hline \multicolumn{8}{|c|}{ Moderate activity (hrs/wk) } \\
\hline \multicolumn{2}{|l|}{ None } & $74 / 508$ & Reference & Reference & $72 / 362$ & Reference & Reference \\
\hline $\begin{array}{l}F< \\
1.5\end{array}$ & $\begin{array}{l}M< \\
1.7\end{array}$ & $8 / 80$ & $0.72(0.37,1.43)$ & $0.67(0.35,1.29)$ & $13 / 72$ & $0.88(0.52,1.48)$ & $0.95(0.58,1.57)$ \\
\hline $\begin{array}{l}F \geq \\
1.5\end{array}$ & $\begin{array}{l}M \geq \\
1.7\end{array}$ & $8 / 77$ & $0.79(0.41,1.51)$ & $0.66(0.35,1.27)$ & $13 / 72$ & $0.96(0.58,1.60)$ & $1.05(0.64,1.70)$ \\
\hline $\mathrm{p}$-trend & & & 0.389 & 0.141 & & 0.859 & 0.868 \\
\hline \multicolumn{8}{|c|}{ Vigorous activity (hrs/wk) } \\
\hline \multicolumn{2}{|l|}{ None } & $85 / 612$ & Reference & Reference & $92 / 442$ & Reference & Reference \\
\hline$F \leq 8$ & $\begin{array}{l}M \leq \\
12\end{array}$ & $5 / 53$ & $1.49(0.69,3.21)$ & $1.30(0.63,2.65)$ & $6 / 64$ & $1.02(0.47,2.21)$ & $1.08(0.54,2.18)$ \\
\hline \multicolumn{3}{|l|}{$\mathrm{p}$-value } & 0.410 & 0.533 & & 0.953 & 0.831 \\
\hline \multicolumn{8}{|c|}{ Recreational activity, total (MET-hr/wk) } \\
\hline \multicolumn{2}{|c|}{ Sedentary } & $32 / 222$ & Reference & Reference & $33 / 202$ & Reference & Reference \\
\hline $\begin{array}{l}F \leq \\
3.7\end{array}$ & $\begin{array}{l}M \leq \\
6\end{array}$ & $19 / 151$ & $0.98(0.55,1.52)$ & $0.96(0.58,1.57)$ & $19 / 100$ & $0.93(0.58,1.50)$ & $1.01(0.63,1.61)$ \\
\hline $\begin{array}{l}F \\
\leq 10.7\end{array}$ & $\begin{array}{l}M \leq \\
18\end{array}$ & $21 / 146$ & $0.96(0.58,1.58)$ & $1.07(0.64,1.81)$ & $23 / 105$ & $1.16(0.74,1.82)$ & $1.16(0.74,1.83)$ \\
\hline $\begin{array}{l}F> \\
10.7\end{array}$ & $\begin{array}{l}M> \\
18\end{array}$ & $18 / 146$ & $0.82(0.50,1.37)$ & $0.78(0.47,1.30)$ & 23/99 & $1.41(0.88,2.23)$ & $1.31(0.84,2.06)$ \\
\hline $\mathrm{p}$-trend & & & 0.481 & 0.318 & & 0.114 & 0.208 \\
\hline \multicolumn{8}{|c|}{$\begin{array}{l}\text { Occupational } \\
\text { activity }\end{array}$} \\
\hline \multicolumn{2}{|c|}{ Sedentary } & $25 / 217$ & Reference & Reference & $23 / 127$ & Reference & Reference \\
\hline \multicolumn{2}{|c|}{ Standing } & 9/93 & $0.85(0.55,1.32)$ & $0.69(0.46,1.05)$ & $37 / 183$ & $0.84(0.54,1.30)$ & $0.89(0.58,1.36)$ \\
\hline \multicolumn{2}{|c|}{ Manual } & $50 / 288$ & $0.70(0.37,1.34)$ & $0.64(0.33,1.24)$ & $35 / 143$ & $1.00(0.68,1.48)$ & $1.13(0.76,1.69)$ \\
\hline \multicolumn{2}{|l|}{$p$-value } & & 0.456 & 0.131 & & 0.663 & 0.532 \\
\hline
\end{tabular}

${ }^{a}$ Model adjusted for age (years), treatment allocation, elastosis of the neck, freckling of the back and skin cancer history

activity and SCC in men observed in this or one other study [16]. Further, it is not fully understood yet how much and what type of physical activity is required to diminish risk of different cancer types [4,32]. Many of the metabolic changes induced by physical activity are mediated through reduced adiposity and effects on other body compartments (e.g. skeletal muscle), and therefore it remains to be determined whether physical activity acts independently of weight control or not $[5,7]$. 
Table 4 Relative risks (RRs) and 95\% Cl of SCC counts (1992-2007) according to type of physical activity, stratified by sex

\begin{tabular}{|c|c|c|c|c|c|c|c|}
\hline \multirow{2}{*}{\multicolumn{2}{|c|}{$\begin{array}{l}\text { Type of physical } \\
\text { activity }\end{array}$}} & \multicolumn{3}{|c|}{ Women } & \multicolumn{3}{|c|}{ Men } \\
\hline & & $\begin{array}{l}\text { Tumour } \\
\text { count }\end{array}$ & $\begin{array}{c}\text { Age-adjusted RR } \\
(95 \% \mathrm{Cl})\end{array}$ & $\begin{array}{c}\text { Multivariable }{ }^{\mathrm{a}} \mathrm{RR} \\
(95 \% \mathrm{Cl})\end{array}$ & $\begin{array}{c}\text { Tumour } \\
\text { count }\end{array}$ & $\begin{array}{c}\text { Age-adjusted RR } \\
(95 \% \mathrm{Cl})\end{array}$ & $\begin{array}{c}\text { Multivariable }^{\mathrm{a}} \mathrm{RR} \\
(95 \% \mathrm{CI})\end{array}$ \\
\hline \multicolumn{2}{|c|}{$\begin{array}{l}\text { Recreational } \\
\text { activity, total (hrs/ } \\
\text { wk) }\end{array}$} & & $(n=665)$ & $(n=650)$ & & $(n=506)$ & $(n=486)$ \\
\hline \multicolumn{2}{|l|}{ None } & 62 & Reference & Reference & 59 & Reference & Reference \\
\hline$F \leq 1$ & $\begin{array}{l}M \leq \\
1.5\end{array}$ & 27 & $0.79(0.42,1.49)$ & $0.89(0.48,1.65)$ & 57 & $1.09(0.58,2.07)$ & $1.03(0.55,1.94)$ \\
\hline$F \leq 3$ & $M \leq 4$ & 29 & $0.91(0.48,1.70)$ & $0.97(0.52,1.79)$ & 41 & $1.18(0.60,2.32)$ & $1.20(0.61,2.35)$ \\
\hline$F>3$ & $M>4$ & 31 & $0.75(0.41,1.39)$ & $0.76(0.42,1.38)$ & 62 & $1.77(0.93,3.37)$ & $1.71(0.91,3.21)$ \\
\hline \multicolumn{2}{|l|}{ p-trend } & & 0.454 & 0.409 & & 0.073 & 0.076 \\
\hline \multicolumn{8}{|c|}{ Walking (hrs/wk) } \\
\hline \multicolumn{2}{|l|}{ None } & 74 & Reference & Reference & 78 & Reference & Reference \\
\hline$F<1$ & $\begin{array}{l}M< \\
1.2\end{array}$ & 28 & $1.21(0.64,2.26)$ & $1.41(0.76,2.62)$ & 30 & $1.06(0.52,2.20)$ & $1.40(0.68,2.89)$ \\
\hline $\begin{array}{l}F< \\
2.5\end{array}$ & $\begin{array}{l}M< \\
3.5\end{array}$ & 14 & $0.60(0.29,1.25)$ & $0.72(0.35,1.48)$ & 52 & $1.99(1.02,3.90)$ & $1.93(0.99,3.76)$ \\
\hline $\begin{array}{l}F \geq \\
2.5\end{array}$ & $\begin{array}{l}M \geq \\
3.5\end{array}$ & 33 & $1.06(0.59,1.90)$ & $1.12(0.63,2.01)$ & 59 & $1.99(1.04,3.81)$ & $1.59(0.85,2.98)$ \\
\hline \multicolumn{3}{|l|}{$\mathrm{p}$-trend } & 0.945 & 0.921 & & 0.027 & 0.149 \\
\hline \multicolumn{8}{|c|}{ Moderate activity ${ }^{1}$ (hrs/wk) } \\
\hline \multicolumn{2}{|l|}{ None } & 121 & Reference & Reference & 157 & Reference & Reference \\
\hline $\begin{array}{l}F< \\
1.5\end{array}$ & $\begin{array}{l}M< \\
1.7\end{array}$ & 17 & $1.00(0.50,2.02)$ & $0.83(0.42,1.65)$ & 33 & $1.18(0.59,2.38)$ & $1.00(0.52,1.92)$ \\
\hline $\begin{array}{l}F \geq \\
1.5\end{array}$ & $\begin{array}{l}M \geq \\
1.7\end{array}$ & 11 & $0.66(0.29,1.50)$ & $0.60(0.27,1.34)$ & 29 & $0.95(0.46,1.96)$ & $1.22(0.59,2.51)$ \\
\hline p-trend & & & 0.325 & 0.192 & & 0.912 & 0.599 \\
\hline \multicolumn{8}{|c|}{ Vigorous activity ${ }^{2}$ (hrs/wk) } \\
\hline \multicolumn{2}{|l|}{ None } & 144 & Reference & Reference & 211 & Reference & Reference \\
\hline$F \leq 8$ & $\begin{array}{l}M \leq \\
12\end{array}$ & 5 & $1.03(0.32,3.27)$ & $0.90(0.29,2.85)$ & 8 & $0.78(0.29,2.09)$ & $0.73(0.27,1.96)$ \\
\hline \multicolumn{2}{|c|}{$p$-value } & & 0.961 & 0.861 & & 0.626 & 0.534 \\
\hline \multicolumn{8}{|c|}{ Recreational activity, total (MET-hr/wk) } \\
\hline \multicolumn{2}{|c|}{ Sedentary } & 62 & Reference & Reference & & Reference & Reference \\
\hline $\begin{array}{l}F \leq \\
3.7\end{array}$ & $M \leq 6$ & 28 & $0.81(0.43,1.51)$ & $0.91(0.491 .68)$ & 59 & $1.05(0.55,2.02)$ & $1.02(0.54,1.94)$ \\
\hline $\begin{array}{l}F \leq \\
10.7\end{array}$ & $\begin{array}{l}M \leq \\
18\end{array}$ & 31 & $0.89(0.48,1.65)$ & $0.98(0.53,1.82)$ & 54 & $1.37(0.72,2.60)$ & $1.35(0.72,2.53)$ \\
\hline $\begin{array}{l}F> \\
10.7\end{array}$ & $\begin{array}{l}M> \\
18\end{array}$ & 28 & $0.74(0.40,1.39)$ & $0.73(0.40,1.33)$ & 57 & $1.64(0.83,3.23)$ & $1.60(0.83,3.09)$ \\
\hline p-trend & & & 0.438 & 0.320 & 49 & 0.125 & 0.134 \\
\hline \multicolumn{8}{|c|}{$\begin{array}{l}\text { Occupational } \\
\text { activity }\end{array}$} \\
\hline \multicolumn{2}{|c|}{ Sedentary } & 35 & Reference & Reference & & Reference & Reference \\
\hline \multicolumn{2}{|c|}{ Standing } & 11 & $0.72(0.42,1.23)$ & $0.53(0.32,0.91)$ & 52 & $0.89(0.49,1.61)$ & $0.92(0.51,1.65)$ \\
\hline \multicolumn{2}{|c|}{ Manual } & 96 & $0.46(0.22,1.10)$ & $0.48(0.22,1.07)$ & 72 & $0.89(0.51,1.53)$ & $0.90(0.53,1.53)$ \\
\hline \multicolumn{2}{|l|}{ p-value } & & 0.155 & 0.027 & 84 & 0.891 & 0.925 \\
\hline
\end{tabular}

${ }^{a}$ Model adjusted for age (years), treatment allocation, elastosis of the neck, freckling of the back and skin cancer history

Some limitations warrant consideration when interpreting results of our study. Due to missing information on physical activity and BMI, we excluded 450 (28\%) participants in the original study cohort which potentially could lead to selection bias. When we compared other study characteristics between those with and without missing data however, we found that the main differences were among men only: men who were excluded were on average 3 years younger than those who were included, and this was reflected in the lower 
actinic damage in the former. Given the lack of differences between women and the lack of any major differences among men who were excluded or included, we believe that any selection bias would be minimal.

The assessment of recreational physical activity relied on self-reports and referred to a time period of two weeks prior to the baseline examination which may not reflect physical activity patterns over an extended time period. However, the questionnaire activity items and the reference time period were adapted from the 1989-90 National Health Survey (NHS) [24] and considered reliable measures. In this study $64 \%$ of the participants reported some form of recreational activity which is similar to the proportion $(65 \%)$ of Queensland adults who reported physical exercise in the 1989-90 NHS [24]. Among Nambour study participants the proportion of people walking was somewhat higher ( $51 \%$ vs $42 \%$ ), and lower for moderate ( $24 \%$ vs $36 \%)$ or vigorous ( $12 \%$ vs $17 \%$ ) activity compared to Queensland data from the NHS. While recreational activity patterns and thus intensity may have differed, the overall level of activity or inactivity in this study was compatible with national data.

Regular sunscreen use has been shown to reduce the occurrence of SCC in this study population [22,33], and thus we routinely adjusted for treatment allocation in all analyses. The known influence of fair skin on both sunscreen use and skin cancer [34] was also accounted for in all analyses and should not have affected results. Further, baseline (1992) sunscreen use was not significantly correlated with recreational or occupational physical activity in men or women and did not differ by case status. The tendency of women to be more regular users with higher recreational activity levels compared to inactive ones observed here and elsewhere [35] would be expected to reinforce an inverse association between physical activity and SCC if it were present, thus lending further weight to the null findings.

\section{Conclusions}

In summary, this prospective study in Australian middleaged adults provides little evidence for the role of recreational or occupational activity in SCC occurrence. Our data are suggestive of a positive association between total hours of recreational activity and SCC in men and show an isolated protective effect of high work activity in women, but these associations are not robust. Since this is the first study on physical activity and SCC, more comparative data are needed to support or refute our findings.

\section{Acknowledgements and funding}

We thank Gail Williams for statistical advice and Maria Celia Hughes for statistical assistance. This research was supported by the National Health and Medical Research Council (NHMRC) of Australia (nos. 442976 and 552429).
ACG is partly supported by a Fellowship from the Medical Research Counci (\#89912).

\section{Author details}

'Queensland Institute of Medical Research, Cancer and Population Studies, 300 Herston Road, Herston, Brisbane 4006, Australia. ${ }^{2}$ School of Translational Medicine, The University of Manchester, Manchester Academic Health Science Centre, Manchester, UK.

\section{Authors' contributions}

$\mathrm{PHL}$ conceived the analysis plan and design, provided technical assistance to statistical analysis, interpreted the data and drafted the manuscript. AR carried out the statistical analysis and participated in the design of the study. ACG conceived of the study, participated in its coordination and helped to draft the manuscript. All authors read and approved the final manuscript.

\section{Competing interests}

The authors declare that they have no competing interests.

Received: 3 August 2011 Accepted: 13 December 2011

Published: 13 December 2011

\section{References}

1. English DR, Armstrong BK, Kricker A, Winter MG, Heenan PJ, Randell PL: Demographic characteristics, pigmentary and cutaneous risk factors for squamous cell carcinoma of the skin: a case-control study. Int J Cancer 1998, 76(5):628-634.

2. Leiter U, Garbe C: Epidemiology of melanoma and nonmelanoma skin cancer-the role of sunlight. Adv Exp Med Biol 2008, 624:89-103.

3. Madan V, Lear JT, Szeimies RM: Non-melanoma skin cancer. Lancet 2010, 375(9715):673-685

4. World Cancer Research Fund/American Institute for Cancer Research (WCRF-AICR): Food, Nutrition, Physical Activity, and the Prevention of Cancer: a Global Perspective. Washington DC: AICR; 2007.

5. McTiernan A: Mechanisms linking physical activity with cancer. Nat Rev Cancer 2008, 8(3):205-211.

6. Friedenreich $C M$, Orenstein MR: Physical activity and cancer prevention: etiologic evidence and biological mechanisms. J Nutr 2002, 132(11 Suppl):3456S-3464S.

7. Friedenreich CM, Neilson HK, Lynch BM: State of the epidemiological evidence on physical activity and cancer prevention. Eur J Cancer 2010, 46(14):2593-2604.

8. Rundle A: Molecular epidemiology of physical activity and cancer. Cancer Epidemiol Biomarkers Prev 2005, 14(1):227-236.

9. Thune I, Furberg AS: Physical activity and cancer risk: dose-response and cancer, all sites and site-specific. Med Sci Sports Exerc 2001, 33(6 Suppl): S530-550, discussion S609-510.

10. Kimlin MG, Martinez N, Green AC, Whiteman DC: Anatomical distribution of solar ultraviolet exposures among cyclists. J Photochem Photobiol B 2006, 85(1):23-27.

11. Moehrle M: Ultraviolet exposure in the Ironman triathlon. Med Sci Sports Exerc 2001, 33(8):1385-1386

12. Moehrle M: Outdoor sports and skin cancer. Clin Dermatol 2008, 26(1):12-15.

13. Lakier Smith L: Overtraining, excessive exercise, and altered immunity: is this a T helper-1 versus T helper-2 lymphocyte response? Sports Med 2003, 33(5):347-364.

14. Dosemeci M, Hayes RB, Vetter R, Hoover RN, Tucker M, Engin K, Unsal M, Blair A: Occupational physical activity, socioeconomic status, and risks of 15 cancer sites in Turkey. Cancer Causes Control 1993, 4(4):313-321.

15. Pukkala E, Poskiparta M, Apter D, Vihko V: Life-long physical activity and cancer risk among Finnish female teachers. Eur J Cancer Prev 1993, 2(5):369-376.

16. Schnohr P, Grønbaek M, Petersen L, Hein HO, Sørensen TI: Physical activity in leisure-time and risk of cancer: 14-year follow-up of 28,000 Danish men and women. Scand J Public Health 2005, 33(4):244-249.

17. Marehbian J, Colt JS, Baris D, Stewart P, Stukel TA, Spencer SK, Karagas MR: Occupation and keratinocyte cancer risk: a population-based casecontrol study. Cancer Causes Control 2007, 18(8):895-908. 
18. Radespiel-Tröger M, Meyer M, Pfahlberg A, Lausen B, Uter W, Gefeller O: Outdoor work and skin cancer incidence: a registry-based study in Bavaria. Int Arch Occup Environ Health 2009, 82(3):357-363.

19. Vågerö $D$, Ringbäck $G$, Kiviranta $H$ : Melanoma and other tumors of the skin among office, other indoor and outdoor workers in Sweden 19611979. Br J Cancer 1986, 53(4):507-512.

20. Green A, Beardmore G, Hart V, Leslie D, Marks R, Staines D: Skin cancer in a Queensland population. J Am Acad Dermatol 1988, 19(6):1045-1052.

21. Green A, Battistutta D, Hart V, Leslie D, Marks G, Williams G, Gaffney P, Parsons P, Hirst L, Frost C, et al: The Nambour Skin Cancer and Actinic Eye Disease Prevention Trial: design and baseline characteristics of participants. Control Clin Trials 1994, 15(6):512-522.

22. Green A, Williams G, Neale R, Hart V, Leslie D, Parsons P, Marks GC, Gaffney P, Battistutta D, Frost $C$, et al: Daily sunscreen application and betacarotene supplementation in prevention of basal-cell and squamous-cell carcinomas of the skin: a randomised controlled trial. Lancet 1999, 354(9180):723-729.

23. Australian Bureau of Statistics (ABS): National Health Survey: Users' Guide. Canberra: ABS; 1991.

24. Australian Bureau of Statistics (ABS): 1989-90 National Health Survey: Exercise, Australia. Canberra:ABS; 1992.

25. Ainsworth BE, Haskell WL, Whitt MC, Irwin ML, Swartz AM, Strath SJ, O'Brien WL, Bassett DR Jr, Schmitz KH, Emplaincourt PO, et al: Compendium of physical activities: an update of activity codes and MET intensities. Med Sci Sports Exerc 2000, 32 (9 Suppl):S498-504.

26. Australian Bureau of Statistics (ABS): Australian Standard Classification of Occupations (ASCO). Canberra: ABS; 1997, Second Edition no. 1220.0.

27. Valery PC, Neale R, Williams G, Pandeya N, Siller G, Green A: The effect of skin examination surveys on the incidence of basal cell carcinoma in a Queensland community sample: a 10-year longitudinal study. J Investig Dermatol Symp Proc 2004, 9(2):148-151.

28. Zou G: A modified poisson regression approach to prospective studies with binary data. Am J Epidemiol 2004, 159(7):702-706.

29. Gardner W, Mulvey EP, Shaw EC: Regression analyses of counts and rates: Poisson, overdispersed Poisson, and negative binomial models. Psychol Bull 1995, 118(3):392-404

30. Green AC, Hughes MC, McBride P, Fourtanier A: Factors associated with premature skin aging (photoaging) before the age of 55: a populationbased study. Dermatology 2011, 222(1):74-80.

31. Frisch RE, Wyshak G, Albright NL, Albright TE, Schiff I: Lower prevalence of non-reproductive system cancers among female former college athletes. Med Sci Sports Exerc 1989, 21(3):250-253.

32. Wannamethee SG, Shaper AG, Walker M: Physical activity and risk of cancer in middle-aged men. Br J Cancer 2001, 85(9):1311-1316

33. van der Pols JC, Williams GM, Pandeya N, Logan V, Green AC: Prolonged prevention of squamous cell carcinoma of the skin by regular sunscreen use. Cancer Epidemiol Biomarkers Prev 2006, 15(12):2546-2548.

34. Green AC, Williams GM: Point: sunscreen use is a safe and effective approach to skin cancer prevention. Cancer Epidemiol Biomarkers Prev 2007, 16(10):1921-1922.

35. Lawler S, Sugiyama T, Owen N: Sun exposure concern, sun protection behaviors and physical activity among Australian adults. Cancer Causes Control 2007, 18(9):1009-1014.

\section{Pre-publication history}

The pre-publication history for this paper can be accessed here: http://www.biomedcentral.com/1471-2407/11/516/prepub

doi:10.1186/1471-2407-11-516

Cite this article as: Lahmann et al:: Prospective study of physical activity and risk of squamous cell carcinoma of the skin. BMC Cancer 2011

11:516.

\section{Submit your next manuscript to BioMed Central and take full advantage of:}

- Convenient online submission

- Thorough peer review

- No space constraints or color figure charges

- Immediate publication on acceptance

- Inclusion in PubMed, CAS, Scopus and Google Scholar

- Research which is freely available for redistribution 